\title{
Robust Gaze-Fixing of an Active Vision System under Variation of System Parameters
}

\author{
Youngmo $\mathrm{Han}^{\dagger}$
}

\begin{abstract}
To steer a camera is done based on system parameters of the vision system. However, the system parameters when they are used might be different from those when they were measured. As one method to compensate for this problem, this research proposes a gaze-steering method based on LMI(Linear Matrix Inequality) that is robust to variations in the system parameters of the vision system. Simulation results show that the proposed method produces less gaze-tracking error than a contemporary linear method and more stable gaze-tracking error than a contemporary nonlinear method. Moreover, the proposed method is fast enough for realtime processing.
\end{abstract}

Keywords: Active Vision, Gaze-Fixing, Orientation Control

\section{시스템 파라미터의 변동 하에서도 강건한 능동적인 비전의 시선 고정}

\author{
한 영 모
}

\section{요 약}

\begin{abstract}
카메라의 시선을 조정하기 위해서는 비전 시스템의 시스템 파라미터를 사용해야 한다. 하지만 이러한 시스템 파라미터는 측정 당시와 사용 중이 달라 질 수 있다. 이 경우 원하는 카메라의 시선 조정이 이루어지기 어렵다. 이 문제를 보완하기 위한 방법으로서 본 연구에서는 LMI(Linear Matrix Inequality)에 기반한 비전 시스템의 시스템 파라미터의 변화에 강건한 시선 고정 방법을 제안한다. 시뮬레이션 검증 결과는 제안하는 방법이 기존의 선형 알고리즘에 비해 더 적은 시선 추적 에러를 보이고, 기존의 비선형 알고리즘에 비해 더 안정적인 시선 추적 에러 를 보인다. 또한 제안하는 방법은 속도가 빨라서 실시간 사용이 가능하다.
\end{abstract}

키워드 : 능동비전, 시선 고정, 방향 제어

\section{1. 서 론}

현재 사용되고 있는 비전 시스템(vision system)의 카메 라는 시야가 좁기 때문에 움직이는 물체를 관측하는 경우 금방 시야에서 놓치게 된다. 이 문제를 해결하는 한 방법 으로서, 카메라의 시선이 관측중인 물체를 따라 움직이도 록 카메라의 각도를 조정하는 시선 고정(Gaze-Fixing)법이 있다. 이처럼 카메라의 방향을 조정할 수 있도록 만든 비 전 시스템을 능동적인 비전(Active Vision) 시스템이라 하 는데, 그 관련 연구가 오래 전부터 수행되었다 $[6,7,8]$. 능

※ 이 논문은 2011년 한양사이버대학교 교내연구비 지원으로 연구되었음 (HYCU-2011-0007).

† 정 회 원 : 한양사이버대학교 컴퓨터공학과 부교수

논문접수: 2012 년 5월 16일

수 정 일 : 1차 2012년 8월 29일, 2차 2012년 9월 28일

심사완료 : 2012년 9월 28일

* Corresponding Author: Youngmo Han(ymhan123@hanmail.net)
동 비전의 좀 더 최근 테마는 참고 문헌 $[1,2]$ 에서 찾아 볼 수 있다.

카메라의 시선을 조정하기 위해서는 비전 시스템의 시스 템 파라미터를 사용해야 한다. 카메라의 시선을 고정하는 대표적인 방법은 카메라의 초점 거리, 회전, 위치 등의 다양 한 시스템 파라미터 정보를 사용하여 물체와의 거리를 추정 하고, 이 거리 정보를 사용하여 카메라의 시선 조종을 수행 한다 $[2,8]$. 하지만 이러한 시스템 파라미터를 정확하게 측정 해 내는 것이 쉽지 않기 때문에, 물체와의 거리 추정에 오 차가 생기게 되고, 그 결과로서 카메라의 시선 조종의 정확 도가 떨어지게 된다. 이를 해결하기 위한 방법으로서 거리 정보를 사용하지 않고 시선 고정점의 위치나 속도와 같은 영상 정보만을 이용하여 카메라의 시선 조종을 수행하는 방 법이 있다[5]. 하지만 이 방법에서도 카메라의 초점 거리, 회 전, 위치 등의 시스템 파라미터에 오차가 있는 경우 영상 
데이터(시선 고정점의 영상 위치와 영상 속도) 측정에 오차 가 생기게 되는데, 이런 경우 그 결과를 보장할 수 없다.

본 논문의 목표는 카메라의 초점 거리, 회전, 위치 등을 포함한 다양한 시스템 파라미터 값의 오차 때문에 발생하는 측정거리 오차나 시선 고정점의 영상 위치와 영상 속도의 측정 오차에도 강건하게 카메라의 시선 조종을 할 수 있는 알고리즘을 설계하는 것이다.

비전 시스템의 시스템 파라미터가 변화해도 강건한 시선 고정을 하는 한 방법으로서, 사용 중에 자동으로 시스템 파 라미터를 측정(Calibration)하고 시선 조종 알고리즘의 이득 (Gain) 값을 보정해 나가는 방법이 있다. 하지만 이러한 방 법은 대부분 복잡한 비선형 알고리즘을 사용해야 하므로 실 시간 사용에 제약이 많다.

이 문제를 보완하는 방법으로서 본 연구에서는 사용 중에 시스템 파라미터를 새로 측정하는 방법 대신, 시선 조정 알 고리즘의 이득(Gain) 값을 시스템 파라미터의 변동 범위 내 에서 강건한 값으로 선택하는 방법을 제안한다. 이를 구현 하기 위해서, LMI (Linear Matrix Inequality) 접근법을 적 용한다.

사실 몇몇 학자들은 $\mathrm{LMI}$ 를 적용하여 시스템 파라미터에 강건한 제어 문제를 연구한 적이 있다 [3]. 하지만 이 연구 의 경우는 비전 분야가 아닌 무인 항공기 제어와 같은 $\mathrm{n}$ 차 원 실수 집합 벡터 공간 $\left(R^{n}\right)$ 에서의 고전적인 제어 문제에 적용한 것이고, 주로 시스템의 안정성(stability) 설계에 초점 을 둔 것이다. 반면 본 연구에서는 이 $\mathrm{LMI}$ 접근법을 비전 시스템에 도입하고, 단순히 $R^{n}$ 벡터 공간에서의 안정성 설 계에 적용하는 것을 넘어서, 단위 구 manifold $\left(S^{2}\right)$ 공간에 서의 카메라의 시선 조정(steering of gaze) 문제에 적용하 는 것으로 연구 범위를 확장한다.

\section{2. 카메라 초점 거리 오차와 시선 고정 점의 거리 오차에 영향 받지 않는 시선 조종 알고리즘 - 단위 구 상의 알고리즘}

시선 조종 알고리즘을 설명하기 전에 먼저 카메라의 시선 조종을 위한 좌표계를 정의해 보자 (Fig. 1 참조).세 개의 축 $I s, J s, K s$ 으로 표현되는 공간좌표계 $\{\mathrm{SF}\}$ 는 공간상에 고 정된 좌표계로서, 원점이 카메라의 렌즈 중심에 있고, $\mathrm{k}^{\text {-축 }}$ (그림에서 $K s$ 로 표시됨)은 이점에서 렌즈에 수직하게 놓여 있다. 카메라는 공간좌표계 $\{\mathrm{SF}\}$ 의 원점을 중심으로 자유롭 게 회전할 수 있으며, 세 개의 축 $I c, J c, K c$ 으로 표현되는 카 메라 좌표계 $\{\mathrm{CF}\}$ 가 부착되어 있다. 편의상 카메라 좌표계 $\{\mathrm{CF}\}$ 의 원점과 공간좌표계 $\{\mathrm{SF}\}$ 의 원점이 일치하도록 놓여 있다. 또한 이미지(image) 평면은 렌즈 중심으로부터 카메라 좌표계 $\{\mathrm{CF}\}$ 의 $\mathrm{k}^{-}$축을 따라 초점거리(focal length) $\mathrm{f}$ 의 거 리에 있다. 이 이미지 평면에는 세 개의 축 $I, \pi, K i$ 으로 표 현되는 이미지 좌표계 $\{\mathrm{IF}\}$ 가 부착되어 있는데, 각 축은 카 메라 좌표계 $\{\mathrm{CF}\}$ 의 각 축과 같은 방향으로 놓여 있다.
주어진 강체 (rigid body) 상의 한 점 $G \in R^{3}$ ( $R^{3}$ 은 3차원 실수 벡터 공간을 의미함)이 경사투영(perspective projection)에 의해 이미지 상에 $q$ 점으로 투영되었다고 하 자. 이 경우 다음의 관계식이 성립한다.

$$
\begin{gathered}
G=[x, y, z]^{T} \\
q=f(G / z)=f[x / z, y / z, 1]^{T}
\end{gathered}
$$

여기서 $x, y, z$ 는 각각 카메라 좌표계 $\{\mathrm{CF}\}$ 에서 바라 본 $G$ 점의 $i, j, k$ 축 방향 성분이다.

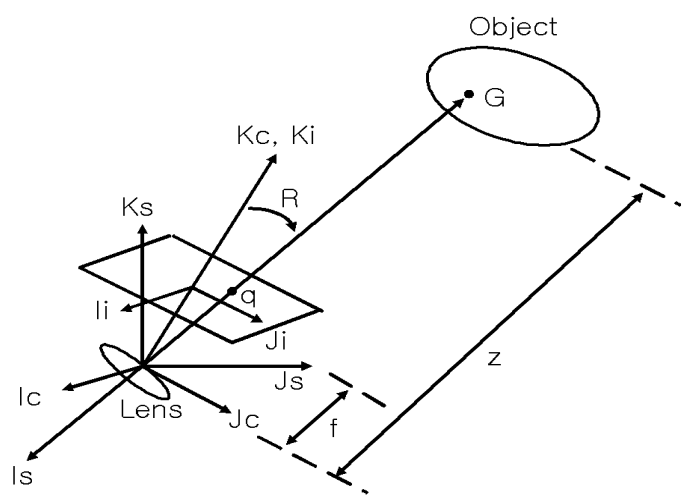

Fig. 1. Active Vision System

이제부터 우리가 원하는 것은 $G$ 점이 항상 카메라의 시선 (line-of-sight) 상에 위치하게 하는 것이다. 다시 말해서 $q$ 점이 항상 이미지 좌표계 $\{\mathrm{IF}\}$ 의 원점에 오게 하고자 한다. 본 논문에서는 편의상 $G$ 점을 시선 고정점 (gaze-fixing point)이라 부르기로 한다. 사실상 시선 고정점은 설계자의 목적에 따라 임의로 선택될 수 있는데, 예를 들어 대상체에 부착된 운동좌표계(body-fixed frame)의 원점을 시선고정점 으로 선택할 수 있다.

이제 우리의 목표는 대상체가 정지해 있든 또는 운동을 하든 상관없이, 항상 $q$ 점이 이미지 좌표계 $\{\mathrm{IF}\}$ 의 원점에 머 무르도록 카메라의 자세(orientation)를 조정하는 효과적인 방법을 찾아내는 것이다. 카메라를 회전행렬 $R \in S O(3)$ (여기서, $R$ 은 회전행렬 rotation matrix의 머리 글자를 딴 것으로서 실수가 아닌 회전 행렬을 나타내는 변수임) 만큼 회전해서 $q$ 점이 이미지 좌표계 $\{\mathrm{IF}\}$ 의 중심에 놓이게 되었다 고 하면 식(1)의 관계가 성립한다.

$$
R \hat{z}=\hat{G}
$$

여기서, $S O(3)=\left\{R \in R^{3 \times 3} \mid R^{T} R=I, \operatorname{det} R=1\right\}, \hat{z}=[0,0,1]^{T}$ 은 카메라 좌표계 $\{\mathrm{CF}\}$ 에서 바라 본 이미지 좌표계 $\{\mathrm{IF}\}$ 의 $\mathrm{Z}^{-}$축 방향의 단위 벡터이고, $G$ 의 좌표가 카메라 좌표계 $\{\mathrm{CF}\}$ 에서 바라 본 값이며, $\hat{G}=G /\|G\|$ 이다. $G=z q / f$ 이므로, $\hat{G}^{\llcorner}=G /\|G\|=(z q / f) /\|z q / f\|=q /\|q\|=\hat{q}$ 가 된다. 따라서, 식(1)은 식(2)와 같이 쓰여질 수 있다. 


$$
R \hat{z}=\hat{q}
$$

여기서 $\hat{q}=q /\|q\|$. 그럼 $q$ 점이 항상 이미지 좌표계 $\{\mathrm{IF}\}$ 의 원점에 오게 하려면 식(2)를 만족하는 회전행렬 $R \in S O(3)$ 을 찾으면 된다. 이 문제 정의에서 주목할 점은 카메라의 보정 자료 $\mathrm{f}$ 와 3 차원 거리 정보 $\mathrm{Z}$ 를 사용하지 않는다는 것 이다.

$q$ 가 식(2)를 만족하게 하는 회전행렬 $R \in S O(3)$ 을 찾기 위해서, 다음과 같은 점근적인(asymptotic) 제어 시스템을 설계하고자 한다.

$$
R(t) \hat{z} \rightarrow \hat{q} \quad \text { as } t \rightarrow \infty
$$

이때 $R(t) \hat{z}$ 은 크기가 항상 1 이므로 사실상 단위 구 $S^{2}=\left\{\Phi \in R^{3} \mid\|\Phi\|=1\right\}$ 의 원소이다. 따라서 본 제어 시스템 설계 문제는 실제적으로 단위 구 상에서의 문제로 이해될 수 있다. 그리고 이러한 단위 구 상의 문제 정의가 카메라 의 보정 정보와 3 차원 거리 정보의 사용을 배제할 수 있는 방법을 제공한다고 볼 수 있다.

$S^{2}$ 상에서 정의된 점근적인 제어 시스템을 설계하기 위해서 먼저 상태변수(state variable) $X$ 를 식(3)과 같이 정의하자.

$$
X=R \hat{z} \in S^{2}
$$

그러면, $\dot{X}$ 는 식(4)와 같은 성질을 갖게 된다.

$$
\dot{X} \in T_{X}\left(S^{2}\right)
$$

여기서 $T_{X}\left(S^{2}\right)$ 는 $X$ 에서의 $S^{2}$ 의 접평면 공간(tangential space)를 나타낸다. $\dot{X}$ 가 $T_{X}\left(S^{2}\right)$ 상에 존재하기 위해서는 식 (5)의 형태로 제어변수 $U \in R^{3}$ 를 정의한다.

$$
\dot{X}=A X+B U
$$

여기서, $A=0, B=\left(I-X X^{T}\right)$

다음으로, $X(t) \rightarrow \hat{q}$ as $t \rightarrow \infty$ 을 만족하는 제어를 설계하 기 위해, 식(6)과 같은 에러 척도를 정의한다.

$$
E=\left(I-X X^{T}\right)(\hat{q}-X)
$$

관계식 $\left(I-X X^{T}\right) X=0$ 를 사용하면, 식(6)은 식(7)과 같이 간단해 진다.

$$
E=\left(I-X X^{T}\right) \hat{q}
$$

\footnotetext{
식 (7)을 시간에 대해 미분하면, $\dot{E}=-\dot{X}\left(X^{T} \hat{q}\right)-X\left(\dot{X}^{T} \hat{q}\right)+\left(I-X X^{T}\right) \dot{\hat{q}} \quad$ 가 된다. 이 식에서,
}

$\left(X^{T} \hat{q}\right), \quad\left(\dot{X^{T}} \hat{q}\right) \quad$ 는 스칼라 양이므로, $\quad\left(X^{T} \hat{q}\right)=\left(\hat{q}^{T} X\right)$, $\left(\dot{X}^{T} \hat{q}\right)=\left(\hat{q}^{T} \dot{X}\right)$ 가 성립한다. 이 관계를 이용하면 식 (7)의 시 간 변화율은 식(8)과 같이 정리된다(식(8)에서 사용된 $I$ 는 $\dot{E}$ 을 식(8)과 같이 인수분해 할 때, “\{\}" 괄호 안의 차원을 맞 추기 위해 도입하였다)

$$
\dot{E}=-\left\{\left(X^{T} \hat{q}\right) I+X \widehat{q^{T}}\right\} \dot{X}+\left(I-X X^{T}\right) \dot{\hat{q}}
$$

여기서, $E(t) \rightarrow 0$ as $t \rightarrow \infty$ 가 되도록 설계하는 전형적인 방법은 $\dot{E}=-K E$ 를 만족하는 양의 정부호(positive definite) 인 제어이득 $K \in R^{3 \times 3}\left(K \in R^{3 \times 3}\right.$ 의 모든 고유치(eigenvalue) 의 실수부가 양수)를 구하는 것이다. 본 논문의 경우, 모 든 양들의 변화 값이 $T_{X}\left(S^{2}\right)$ 상에 존재해야 한다는 점을 고 려하여,

$$
\dot{E}=-\left(I-X X^{T}\right) K E
$$

를 만족하고, $\left(I-X X^{T}\right) K$ 가 양의 정부호(positive definite) 가 되도록 제어이득 $K \in R^{3 \times 3}$ 를 구하는 문제로 수정한다.

식(5)를 사용하면, 식 (8)이 $\dot{E}=-\left(I-X X^{T}\right) K E$ 를 만족하기 위해서는 제어 변수가 식(10)을 만족해야 함을 알 수 있다.

$$
\left(I-X X^{T}\right) U=\left\{\left(X^{T} \hat{q}\right) I+X \widehat{q}^{T}\right\}^{-1}\left(I-X X^{T}\right)(\dot{\hat{q}}+K E)
$$

양변에 $\left(I-X X^{T}\right)$ 를 곱하고, $\left(I-X X^{T}\right)\left(I-X X^{T}\right)=\left(I-X X^{T}\right)$ 의 관계를 사용하면 식(11)과 같이 정리된다.

$$
\left(I-X X^{T}\right) U=\left(I-X X^{T}\right)\left\{\left(X^{T} \hat{q}\right) I+X \chi^{T}\right\}^{-1}\left(I-X X^{T}\right)(\dot{\hat{q}}+K E)
$$

식(11)을 만족하는 한 선택은 식(12)와 같다.

$$
U=-\left\{\left(X^{T} \hat{q}\right) I+X \widehat{q^{T}}\right\}^{-1}\left(I-X X^{T}\right)(\dot{\hat{q}}+K E)
$$

식(5)와 식(12)는 단위 구 상에서 정의됨으로써, 카메라의 초점 거리와 같은 보정 파라미터 값과 시선 고정점의 거리 파라미터를 포함하고 있지 않다. 따라서 이 시선 조종 알고 리즘은 카메라의 보정 파라미터와 시선 고정점의 거리 파라 미터의 오차나 변동에 영향 받지 않는다.

\section{3. 시선 고정 점의 영상 위치와 속도 오차에 강건한 제어 이득(Control Gain) 계산 - LMI 방법 적용}

식(12)를 살펴보면, 시선 고정점의 영상 위치 $q$ 와 속도 $\dot{q}$ 를 포함하고 있다. 따라서 영상 위치 $q$ 와 속도 $\dot{q}$ 의 측정값 
에 오차가 존재하면, 상태 변수 $X$ 의 추정 값이 참값과 달 라지고, 그 결과로서 식(5)의 시스템 변수 $A=0, B=\left(I-X X^{T}\right)$ 의 추정 값이 참값과 달라질 수 있다. 이 런 경우에도 식(5)와 식(12)가 원활하게 시선 조종을 할 수 있도록 (계산된 상태 변수 $X$ 가 원하는 값 $\hat{q}$ 로 다가갈 수 있록) 제어 이득 $K \in R^{3 \times 3}$ 를 설계하고자 하는 것이 본 절 의 목적이다. 이를 위해 LMI 방법을 도입하고자 한다.

$\mathrm{LMI}$ 가 기존에는 안정성(stability) 제어 문제에 주로 적용 되었다. 그 내용을 잠시 살펴보면 다음과 같다. 시스템 $\dot{X}^{\prime}=A^{\prime} X^{\prime}+B U^{\prime}$ 에 상태 피드백 (state feedback) 제어 $U^{\prime}=K^{\prime} X^{\prime}$ 를 적용하는 경우를 생각해 보자. 그 결과 식(13) 의 닫힌 루프 시스템(closed-loop system)을 얻게 된다.

$$
\dot{X}^{\prime}=\left(A^{\prime}+B^{\prime} K^{\prime}\right) X^{\prime}
$$

정리 1 [3]: 식(12)에 표현된 상태 피드백 제어에 의한 닫 힌 루프 시스템의 고유치(eigenvalue)들이 모두 식(14)에 정 의된 볼록 구역 (LMI 구역)에 존재할 필요충분조건은 식 (15)를 만족하는 양의 정부호(positive definite)인 $m$ 차원 복소 변수 $Y^{\prime}, X^{\prime}$ 가 존재하는 것이다.

$$
D=\left\{Z \in C^{m}: L+M Z+M^{T} Z<0\right\}
$$

여기서, $L=\left\{\alpha_{i, j}\right\}_{1 \leqq i, j \leqq m}, M=\left\{\beta_{i, j}\right\}_{1 \leqq i, j \leqq m} \in R^{m \times m} \quad$ ( $L$ 과 $M$ 은 $m$ 행, $n$ 열로 이루어진 실수 행렬이고, 각각의 $i$ 행 $j$ 열 의 원소는 $\alpha_{i, j}$ 와 $\beta_{i, j}$ 로 표현된다), $L=L^{T}$ 을 만족하는 행렬 이다. 사용자가 원하는 제어의 조건들을 볼록 구역 $D$ 의 형 태로 표현한다. 그리고 이렇게 정의된 볼록 구역 $D$ 를 잘 묘 사하도록 행렬 $L, M$ 이 선택된다.

$$
\begin{gathered}
M_{D}=\left\{\alpha_{i j} X^{\prime}+\beta_{i j}\left(A^{\prime} X^{\prime}+B^{\prime} Y^{\prime}\right)\right. \\
\left.+\beta_{i j}\left(X^{\prime} A^{\prime T}+Y^{T} B^{\prime T}\right)\right\}<0
\end{gathered}
$$

여기서, $\quad \alpha_{i, j}$ 와 $\beta_{i, j}$ 는 식 (14)에서 정의된 값이고, $A^{\prime}, B$ 은 식 (13)에서 정의된 값이다. $Y^{\prime}, X^{\prime}$ 은 식 (15)의 부등식을 만족하도록 선택 되어야하는 양의 정부호(positive definite) 인 $m$ 차원 복소 변수이다.

그러면, 상태 피드백 이득(state feed gain)은 식(16)과 같 이 주어진다.

$$
K^{\dagger}=Y^{\dagger} X^{\prime-1}
$$

본 논문에서는 기존에 주로 안정성 제어 문제에 적용 되던 LMI 접근법을 식(5)의 시선 추적(tracking) 문제에 도 확대 적용하는 방법을 제안하고자 한다. 그 아이디어 는 다음과 같다. 식(5)에 표현된 시선 추적 조정 문제는 식(12)에 표현된 제어값을 사용함으로써, 식(9)의 제어 이 득 $K \in R^{3 \times 3}$ 의 설계 문제로 귀결된다. 편의상
$X^{\prime}=E, \quad A^{\prime}=0, \quad B=\left(I-X X^{T}\right), \quad K^{\prime}=-K$ 로 매개 변수를 정의하면, 식(9)는 식(13)로 귀결된다. 따라서 위에서 설명한 LMI 기법을 식(9)에 적용할 수 있다.

식(13)의 제어 이득 계산에서, 선형제어 방식은 선형 알고 리즘을 사용하여 제어 이득을 계산하지만, 제안하는 LMI 방 식은 LMI 도구를 사용하여 제어 이득을 계산한다. 이처럼 선형제어 알고리즘이나 제안하는 LMI 방식은 같은 시스템 식 (식(13))을 사용한다. 따라서 제어 이득 변수의 추가나 차원의 변화는 없다. 선형 제어 방식은 제어 이득을 계산할 때 선형으로 근사화된 단순한 계산법을 사용하므로 계산량 이 적은 장점이 있지만 선형화 오차가 생기게 되고 시스템 파라미터의 오차에 대해 보정을 하기 어렵다는 단점이 있 다. 반면, 제안하는 $\mathrm{LMI}$ 방식은 $\mathrm{LMI}$ 최적화를 통해 제어 이득을 계산하므로 계산량이 조금 증가하는 단점이 있지만, 시스템 파라미터의 오차에 대한 보정을 최적화를 통해 수행 할 수 있어 좀 더 신뢰도가 높은 제어 이득이 가능하다는 장점이 있다.

\section{4. 성능 평가와 검증}

본 절에서는 본 논문에서 제안한 방법의 성능을 검증해 보고자 한다. 먼저 제안한 방법의 특이점 배치(singular configuration)를 분석함으로써 좀 더 잘 되는 경우와 안 되 는 경우를 고찰해 보고, 다음으로 일반적인 배치(normal configuration)에 대해 정량적으로 그 성능을 평가해 본다. 식 (6)을 살펴보면, $\left(I-X X^{T}\right)$ 는 $X$ 에서의 접평면 $(X$ 에 수직 한 평면)으로의 투영 행렬(projection matrix)이므로, 결국 에러 지표 $E$ 는 $(\hat{q}-X)$ 가 $X$ 에서의 접평면으로 투영된 값이 다. 따라서, $(\hat{q}-X)$ 의 값이 $X$ 와 평행한 경우(목표 위치 $\hat{q}$ 가 카메라의 현재 위치 $X$ 와 같은 방향이거나 반대 방향인 경 우)에 에러 지표 $E$ 가 무조건 0 이 되어 본 알고리즘이 적용 될 수 없게 된다. 목표 위치 $\hat{q}$ 가 카메라의 현재 위치 $X$ 와 같은 방향인 경우는 이미 추적이 완료된 상태를 의미하므로 문제가 없다. 결국 본 논문에서 제안한 방법은 목표 위치 $\hat{q}$ 가 카메라의 현재 위치 $X$ 와 반대 방향인 경우에 특이 배 치가 되어 적용이 안 됨을 알 수 있다. 따라서, 이러한 특이 배치에 가까울수록 제안한 방법이 잘 안되고, 이 특이 배치 에서 멀수록 잘 됨을 알 수 있다.

다음으로 일반적인 배치(normal configuration)에 대해 정 량적인 성능을 평가해 본다. 본 절에서 성능 평가 지수로는 식 (6)의 추적 에러(tracking error)를 선택하였다. 여기에 덧붙여, 식(12)의 영상 위치 $q$ 와 속도 $\dot{q}$ 의 측정값에 오차가 존재하여, 상태 변수 $X$ 의 추정 값이 참값과 달라지고, 그 결과로서 식(5)의 시스템 변수 $A=0, B=\left(I-X X^{T}\right)$ 의 추정 값이 참값과 달라지는 상황을 설정하였다. 이 시나리오에서 는 상태변수 $X$ 의 추정 값 오차 범위가 $\mathrm{x}, Z^{-}$축을 중심으로 참값보다 5 도 만큼 다를 수 있다고 가정하였다. 이러한 시 스템 변수의 추정 값 오차 범위 하에서도, 식(12)의 
$\left(I-X X^{T}\right) K$ 의 고유치들이 모두 복소평면의 좌측에 존재하 도록 하는 제어 이득 $K$ 를 MATLAB의 LMI 도구 상자(tool box)를 이용해 구하였다. 본 모의실험은 $2 \mathrm{GHz} \mathrm{CPU}, 1 \mathrm{G}$ $\mathrm{RAM}$ 을 장착한 Pentium $\mathrm{PC}$ 에서 수행하였다.

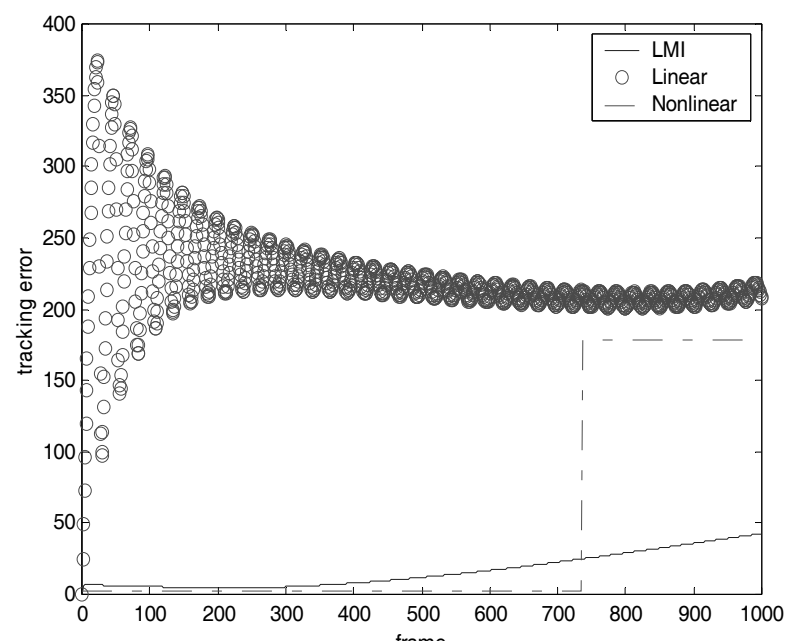

Fig. 2. Gaze-Steering Error Values. The horizontal axis denotes time(image frame), and the vertical axis denotes tracking error values(equation (6)). Here, tracking error denotes tracking error between the camera and the gaze-steering point. And LMI, Linear, Nonlinear denote LMI method, Linear method and Nonlinear method, respectively.

시선 추적의 결과는 Fig. 2에 주어져 있다. 그리고 본 모 의실험(simulation) 중의 계산시간의 평균치는 Table 1 에 주 어져 있다. 비교를 위해 본 논문에서 제안하는 카메라의 시 선제어 알고리즘을 기존의 선형제어 방법과 비교해 보자. 이 선형 제어 방법은 참고문헌 [4]에서 기술된 시각적 추적 시스템(visual tracking system)의 모델을 선형화 한 후 PD 제어 (Proportional-Derivative control, 비례 미분 제어) 법 칙을 적용한 것이다. 또한 제안하는 알고리즘을 기존의 비 선형 제어 방법 [1]과도 비교한다. 이 비선형 방법에서는 매 시간 영상 위치와 속도를 비선형 알고리즘을 사용하여 정확 히 측정하고, 그 결과를 통해 제어 법칙을 설계한다.

Fig. 2와 Table 1 을 살펴보면, 본 논문에서 제안한 방법 이 선형 제어 방법에 비해 추적에러가 상당히 적음을 알 수 있다. 그 이유는 다음과 같다. 선형 제어 방법의

추적 에러는 크게 두 가지로 구성되는데, 하나는 잡음 (noise)에 의한 것이고 또 다른 하나는 모델의 선형화에서 비롯된 것이다. 그리고 후자의 에러가 전자의 것보다 상당 히 크다. 이와 같은 선형 제어 방법의 경우와는 대조적으로 본 논문에서 제안한 방법에서는 추적에러의 요인이 잡음 (noise)에 의한 것 하나 뿐이다. 비선형 방법은 제안하는 방 법에 비해 적은 추적 에러를 보이다가 후반 부에 급격히 에 러 값이 커져서 제안하는 방법의 에러 값보다 커지는 것을 볼 수 있다. 비선형 방법의 에러 값의 원인으로는 파라미터 추정을 위한 데이터를 충분히 많이 사용하지 않은 경우와
초기치 설정 오류를 생각할 수 있다. Fig. 2에서는 초반 부 에 비선형 방법이 적은 에러를 보여 주므로, 파라미터 추정 을 위한 데이터는 충분히 사용한 것으로 생각할 수 있다. 후반부에 결과가 나빠지는 원인은 초기 설정 오류가 커지기 때문이다. 그 이유는 비선형 방법은 초기화를 필요로 하는 데, 이 초기화 값으로 이전 프레임의 정보를 사용하게 된다. 그리고 시간이 지날수록 초기화 에러 값이 누적되어, 적절 한 초기화가 되지 못하므로 비선형 방법이 올바른 값으로 수렴하지 못하기 때문이다. 물론, 초기치 설정을 위해 이전 프레임보다 더 이전의 프레임들을 사용한다면 좀 더 나은 결과를 가져올 수도 있을 것이다. 하지만 이 경우 계산량이 급증하게 되는 단점이 발생한다.

반면, 제안하는 방법은 비선형 방법에 비해 시간에 대해 더 안정적인 시선 조종 결과를 보여줌으로써, 추적 시간이 길어질 경우 비선형 방법에 비해 유리하다.

Table 1은 본 논문에서 제안한 방법이 비선형 제어 방법 에 비해 계산 시간이 훨씬 적음을 보여준다. 비록 선형 제어 방법보다는 계산 시간이 더 걸리지만, 초당 100 프레임 정도 를 처리함으로써 실시간 사용이 가능함을 보여주고 있다.

Table 1. Average value of computation time

\begin{tabular}{|c|c|}
\hline & 계산시간 $(\mathrm{sec})$ \\
\hline 제안하는 방법 & 10.9060 \\
\hline 기존의 선형 방법 & 0.7340 \\
\hline 기존의 비선형 방법 & 223.0310 \\
\hline
\end{tabular}

\section{5. 결 론}

본 논문에서는 이미지 좌표와 이미지 속도가 측정 가능 할 때, 대상체 상의 한 점에 카메라의 시선을 점근적으로 고정할 수 있는 시선 조종 알고리즘을 제안하였다. 본 제어 방법은 다음의 세 가지 장점을 가지고 있다. 첫째, 카메라 의 보정 파라미터와 시선 고정점의 거리 파라미터의 측정 오차에 의한 시스템 파라미터의 변동에 영향 받지 않는다. 둘째, 시선 고정점의 영상 위치와 속도 파라미터의 측정 오 차에 의한 시스템 파라미터의 변동에 강건하다. 셋째, 시선 조종 방법이 매우 쉽고 뺄라서 실시간 사용(real-time processing)이 가능하다.

\section{참 고 문 헌}

[1] Hao, M, Deuflhard, P., Sun, Z., Fujii M., "Model-free uncalibrated visual servoing using recursive least squares," ournal of Computers, Vol.3, No.11, pp.42-50, November, 2008.

[2] Nakagawa, M., Adachi, E., Takase, R., Okamura, Y., Kawai, Y., Yoshimi, T., Tomita, F., "Gaze tracking control using an active stereo camera," The International Archives of the 
Photogrammetry. Remote Sensing and Spatial Information Sciences, Vol.XXXV. Part B3b, pp.387-392, 2008.

[3] Chilali, M., Gahinet P., " $H_{\infty}$ Design with pole placement constraints: an LMI approach," IEEE Trans. Automatic Control, Vol.41, No.3, pp.358-367, 1996.

[4] Papanikolopoulos, Khosla, P. K., Kanade T., "Visual tracking of a moving target by a camera mounted on a robot: A combination of control and vision," IEEE Transactions on Robotics and Automation, Vol.9, No.1, pp.14-35, 1993.

[5] Youngmo Han, "Steering Gaze of a Camera in an Active Vision System: Fusion Theme of Computer Vision and Control", Journal of The Institute of Electronics Engineers of Korea, Vol.41, No.298, pp.39-43, July, 2004.

[6] Pellkofer, M., Dickmanns, E. D., "EMS-vision: gaze control in autonomous vehicles", Proceedings of the IEEE Intelligent Vehicles Sympositum 2000, pp.296-301, October 3-5, 2000.

[7] Tordoff, B., Murray, D., "Reactive control of zoom while fixating using perspective and affine camera", IEEE Transactions on Pattern Analysis and Machine Intelligence, pp.98-112, January, 2004.

[8] Hemayed, E. E., Ahmed, M. T., Farag, A. A., "CardEye: a $3 \mathrm{D}$ trinocular active vision system", IEEE Conference on Intelligent Transportation Systems, pp.398-403, October 1-3, 2000.

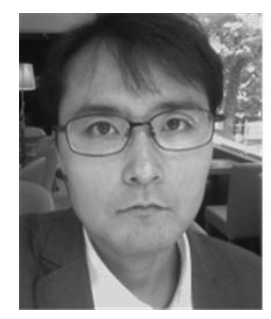

\section{한 영 모}

e-mail : ymhan123@hanmail.net 1992년 서울대학교 물리교육학과(이학사) 1995년 서울대학교 제어계측공학과(공학사)

1998년 서울대학교 전기공학부(공학석사, 신호처리, VLSI 설계 전공)

2002년 서울대학교 기계항공공학부(공학박사, 컴퓨터비전, 인체 영상의 자세 인식, 로봇 제어 전공)

2002년 2003년 세종-록히드마틴 우주항공연구소 전임연구원, 전임연구교수

2004년 2005년 이화여자대학교 정보통신공학과 연구전임강사, 연구교수

2006년 현 재 한양사이버대학교 컴퓨터공학과 전임강사, 조교수, 부교수

2007년 현 재 International Biographical Centre (England), Deputy Director General 및 Honorary Director General

2007년 현 재 World Congress of Arts, Science and Communications (England), Vice President

2009년 현 재 American Biographical Institute Research Association (USA), Deputy Governor

관심분야: 컴퓨터비전 응용 멀티미디어 및 생체 영상 인식, 모 바일 및 로봇 임베디드 시스템 소프트웨어, 인간과 컴퓨터의 시각적 인터페이스, 정보 기술을 위한 통합 과학적 접근법 